\title{
WEB
}

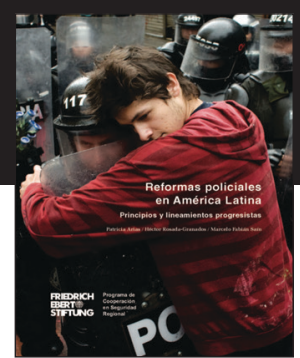

Patricia Arias / Héctor Rosada Granados /

Marcelo Fabián Saín. "Reformas policiales en América Latina principios y lineamientos progresistas".

Recuperado de: http://library.fes.de/pdf-

files/bueros/la-seguridad/09383.pdf

\section{Reformas policiales en América Latina principios y lineamientos progresistas}

El libro hace parte de las publicaciones del Programa de Cooperación en Seguridad Regional del Observatorio de Crimen Organizado en América Latina y el Caribe de la FES, encargado de apoyar las actividades que realizan grupos de trabajo, nacionales o regionales, que analizan y debaten asuntos de geopolítica, defensa y seguridad regional y pública.

Los autores plantean que en América Latina desde la década de los noventa, se han venido generando procesos de reforma en las fuerzas policiales, atendiendo a las nuevas condiciones de democracia de los diferentes países, la generación y mutación del delito, así como la responsabilidad de las instituciones policiales frente a las nuevas demandas de seguridad ciudadana. Reformas que en su gran mayoría fueron parciales, careciendo del apoyo político y enfrentando resistencia interna en cada institución policial, por lo tanto no se pudieron desarrollar con la amplitud y profundidad requerida.

El libro presenta principios y propuestas de cómo debería ser la policía y sus modelos organizacionales, los cuales se estructuran con base a las funciones que por misionalidad deben cumplir, teniendo en cuenta los componentes de la nueva policía y sus relaciones con la comunidad y autoridades civiles.

Se presenta un análisis del contexto de la reforma policial, visto desde los antecedentes históricos, es así como a mediados de las década de los ochenta y principios de los noventa América Latina vivió una serie de procesos que determinaron la dinámica de los intentos de reforma y fortalecimiento de los sectores de seguridad en la región. En este período se terminaron algunos conflictos armados internos y se firmaron acuerdos de paz en Centroamérica, al mismo tiempo en algunos países de Suramérica se retornaba a la democracia. Paralelo a ello en la gran mayoría de los países se generaron cambios profundos en sus economías, cambios que se evidenciaron en la desigualdad tanto económica y social, trayendo como resultado el desempleo y la informalidad. Esto hizo aumentar la percepción 
de inseguridad de la ciudadanía, lo que sumado a su vulnerabilidad frente a la corrupción generó gran desconfianza hacia las instituciones policiales.

Desde la seguridad en América Latina, los autores presentan algunos datos contundentes; y que se recogen en la siguiente cita textual:

"Cifras de homicidios en 2010, la tasa por cada 100.000 habitantes de $(15,6)$, superada solo por África $(17,4)$ y muy por encima del promedio mundial $(6,9)$. La victimización, indicador que muestra el número de personas que reportan, aunque no necesariamente denuncian, haber sido asaltadas, agredidas o víctimas de algún delito, ha sido medida por el Latinobarómetro desde 1995. Entre ese año y 2001 creció significativamente, al pasar de $29 \%$ a $43 \%$, para caer a 32\% en 2006. Desde ese momento ha fluctuado ligeramente, y en 2010 era de $31 \%$ (Costa, 2012). (P. 10)"

Ante este panorama de inseguridad y la poca efectividad de las autoridades, el ciudadano buscó nuevas formas de auto protección, entre las cuales se optó por separarse de los espacios políticos, como lo mencionan los autores "renunciando a su derecho de participar en un nuevo ordenamiento democrático, evadiendo también la actividad pública, el confinamiento en su hogar, la compra de protección privada, con más riesgo que seguridad, y el incremento en la adquisición de armamento" (P. 14).

Las instituciones policiales y su funcionamiento pasaron a ser en la agenda pública de suma importancia en razón del impacto público que genera la inseguridad en cada país. Las policías latinoamericanas son muy diversas en su estructura y funcionamiento, no es posible identificar un modelo único, en países como Argentina y México hay diversos cuerpos de policía entre los cuales no existe coordinación, de igual forma existen países como Colombia, Guatemala y El Salvador que tienen un único cuerpo policial, sin embargo, históricamente la estructura funcional de todos estos cuerpos ha sido muy centralizada, jerarquizada y militarizada, esto ha sobrecargado de funciones y tareas administrativas, dificultando la comunicación entre los niveles jerárquicos.

En Brasil, Honduras, México y otros países, la investigación de delitos es tarea de las policías judiciales, y las labores de prevención son asumidas por una policía distinta, en Perú y en buena parte de las provincias de Argentina, la investigación y la prevención están a cargo de un solo cuerpo policial. En conclusión el elemento común que se presenta en la mayoría de los países de la región, es que no existe claridad en cuanto a las funciones de seguridad pública, hay carencia en diferenciar lo que deben cumplir 


\section{WEB}

las fuerzas policiales y las militares, ya que tradicionalmente han venido realizando tareas de seguridad pública. Esta falta de claridad ha generado que las funciones se superpongan y actualmente muchas policías operan con base a doctrinas militares lo cual ha impactado su comportamiento frente a la ciudadanía, llevado a numerosas violaciones de derechos humanos en razón de la naturaleza de las funciones militares y un entrenamiento que no los prepara para la interacción con la comunidad.

Es importante entender que la formación, el entrenamiento y la capacitación deben ir orientados a atender las modalidades de policía y su impacto sobre el delito, actualmente se da más importancia a la estructura organizativa, bases doctrinales, orientaciones, funciones, equipamiento e infraestructura. Actualmente se privilegian carreras profesionales de diferentes disciplinas, dejando a un lado la esencia policial, existe la necesidad de desarrollar temáticas que permitan formar a un profesional en policía, que tenga los conocimientos necesarios para dar respuesta a las necesidades de seguridad que la comunidad requiere.

Se plantea, entre los obstáculos que no permiten una reforma adecuada de las policías de Latinoamérica, los siguientes: a) La ausencia de un diagnóstico institucional integral y adecuado de las policías, se desconoce casi por completo su cultura institucional, sus bases doctrinales y sus formas de concebir e interpretar su trabajo; b) Falta de dispositivos políticos e institucionales especializados en la dirección y administración de las policías, porque esas funciones han sido ejercidas por sus cúpulas, sin injerencia político institucional externa; c) El desconocimiento gubernamental y político de las prácticas y mecanismos corruptivos de la policía, los gobiernos, y la dirigencia política en general; d) Finalmente, el último obstáculo es una visión política de la reforma policial que la considera un proceso institucional complejo cuyo desarrollo no reportará réditos políticos tangibles e inmediatos.

Existe desconfianza en las instituciones policiales de Latinoamérica, la presión política, ciudadana y mediática ha llevado a que se den los espacios para la participación de los militares en asuntos de seguridad pública, incluso por fuera de los estados de excepción, como lo plantean los autores.

Se requiere de decisiones estratégicas de política criminal que no pueden quedar al azar ni ser coyunturales, por las consecuencias de incorporar en tareas de seguridad pública a estamentos cuya formación responde a lógicas y fines muy distintos de aquellos para los cuales existen los cuerpos policiales. Además, el cuidado y fortalecimiento de las instituciones supone el resguardo de sus funciones, por lo que deben hacerse todos los 
esfuerzos para que el rol policial y el de las fuerzas armadas se establezcan con la mayor claridad. (p. 23).

Hay dos conclusiones que plantean los autores del porqué es necesaria la diferenciación de roles:

"Las fuerzas armadas están entrenadas y organizadas bajo la lógica de destruir al enemigo, para lo cual se enfatiza la jerarquía, la disciplina, la obediencia y lealtad, y la reserva y el secreto de sus acciones. Además, en la mayoría de los países latinoamericanos los ejércitos han tendido a resistirse a la supervisión y el control civil".

"Ias policías son entrenadas y organizadas para resolver problemas, prevenir y controlar el delito, así como para mantener el orden público, operando en cercana colaboración con la sociedad y haciendo un uso proporcional de la fuerza al cumplir con sus tareas. La policía debe ser receptiva a los controles del gobierno y de la sociedad civil, sus acciones son visibles y están sujetas al escrutinio público". (p. 24).

Se plantea un modelo de policía ideal con algunas características esenciales:

La policía, elemento fundamental en la construcción de un Estado fuerte y legítimo, las instituciones policiales hacen parte de un sistema político, siendo éste uno de los bienes o servicios que este produce y entrega al entorno social, como institución depositaria de un poder excepcional que le permite hacer uso de la fuerza para cumplir con su fin. Los autores plantean "como instrumento del poder que le asigna su misión y funciones, es un servicio público visible que debería ser accesible al requerimiento de todos, y, también, un cuerpo profesional con intereses y problemas propios" (p.25). Siendo parte de los controles sociales organizados e institucionalizados del Estado, la policía tiene como tarea hacer uso de la fuerza para contrarrestar las presiones sociales externas que conducen a las personas a actuar en contra de las normas establecidas.

Una institución desmilitarizada. Se plantea que la desmilitarización de la policía implica reformular sus bases simbólicas y su estructura orgánica y funcional, concibiéndola como institución civil armada.

Pública, civilista y no política. Las policías en Latinoamérica tienen un carácter público lo cual demanda autonomía frente a presiones, intereses y agendas de cualquier naturaleza, para garantizar su vocación como cuerpo profesional que presta un servicio público y evitar su conversión en instrumento de intereses ajenos a su misión fundamental. Su carácter civil 


\section{WEB}

determina que las funciones policiales estén claramente definidas dentro del ámbito de la seguridad pública, de acuerdo con lo establecido por la ley. La institución debe ser por tanto un organismo público políticamente neutro.

Con claridad en sus funciones. Las funciones de las instituciones policiales deben orientarse a la prevención policial y la investigación criminal, la estructura institucional ha de ser clara en cuanto al cumplimiento de cada función y los perfiles adecuados para desempeñarlas, e incluir instancias de coordinación entre ellas.

Con un modelo y estructura orgánica apropiados. Actualmente la gran mayoría de estructuras de las instituciones policiales son rígidas y jerárquicas. El modelo de estructura debe corresponder a sus funciones básicas, con elementos de gestión que definan sus funciones, mecanismos de coordinación interinstitucional, procesos y procedimientos e indicadores que permitan medir la eficacia y la eficiencia del accionar policial.

Formada y capacitada adecuadamente. Es necesario realizar nuevos modelos policiales los cuales deben estar ajustados a una carrera policial definida, esto va de la mano con la formación que requiere el funcionario de policía para un desempeño adecuado en el campo institucional. Como lo plantean los autores "el diseño y la enseñanza de los programas de formación, profesionalización y especialización del recurso humano destinado a las diversas labores policiales" (p.32).

Bien equipada. Para que un cuerpo de policía pueda cumplir sus funciones adecuadamente es necesario garantizar el presupuesto requerido, como el gasto en equipamiento, estableciendo la necesidad y conveniencia de su adquisición. Esto se debe hacer con indicadores coherentes con los objetivos y metas en materia de seguridad.

Cercana a los gobiernos locales y con proximidad a la comunidad. Es recomendable por razones de tipo operativo que los nuevos modelos de policía sean descentralizados en materia de potestades y recursos, todo mediante un proceso paulatino de coordinación con sus autoridades, con el fin de alimentar los procesos locales de decisión. De igual forma es necesario establecer y consolidar las relaciones entre la institución y las comunidades, mediante una labor respetuosa y eficiente de los cuerpos policiales. Todo mediante la legitimidad y confianza hacia su policía, mediante la construcción de confianza por parte de la ciudadanía habrá mayor información o ayuda, se presentarán las denuncias sobre asuntos que lo ameriten. 
Por otro lado, cuando se habla de reforma policial se debe tener en cuenta que es un proceso complejo que implica reestructuración desde lo doctrinal, orgánica y funcional, se plantean ocho dimensiones fundamentales para los cambios institucionales: a) Las funciones de la institución policial y del trabajo policial; b) La organización; c) La profesión policial; d) La educación; e) La formación; f) La profesionalización del reclutamiento; g) La infraestructura y el equipamiento; h) El control y la evaluación.

En concusión para las democracias latinoamericanas la reforma policial es una tarea pendiente, aunque ya algunas han sido reformadas es necesario entender que implica un cambio institucional mucho más amplio y complejo, no solo desde lo doctrinal, organizativo y funcional, sino que debe darse desde el modo tradicional de relacionamiento con las autoridades gubernamentales y el trabajo con la ciudadanía.

Es pertinente afirmar que muchos cuerpos de policía de Latinoamérica están diseñados para atender los casos una vez ocurren, las policías deben orientar su formación a la prevención del delito, un trabajo más comunitario, la formación debe ser más integral, además de la investigación criminal, es necesario formar líderes que mediante un trabajo conjunto con la ciudadanía, puedan prevenir y evitar la comisión de delitos.

Asumir que una política de seguridad pública democrática implica que los responsables en los gobiernos, junto con las instancias competentes de la sociedad civil, "generen estrategias inclusivas e integrales de gestión de los conflictos", abordando la problemática criminal desde un ordenamiento jurídico acorde, con instituciones policiales altamente efectivas.

En concusión para las democracias latinoamericanas las reformas policiales es una tarea pendiente, aunque ya algunas han sido reformadas es necesario entender que implica un cambio institucional mucho más amplio y complejo, no solo desde lo doctrinal, organizativo y funcional, sino que debe darse desde el modo tradicional de relacionamiento con las autoridades gubernamentales y el trabajo con la ciudadanía. Lo cual requiere el compromiso no solo de la institución, es necesario contar con la participación del estamento político de cada país, teniendo en cuenta la importancia que implica para una sociedad, contar con un cuerpo de policía que dé respuesta oportuna y acorde a las necesidades de convivencia y seguridad pública.

Sinopsis elaborada por Mayor Germán Rafael Sierra Chaparro Vicerrector Académico - DINAE Policía Nacional de Colombia. 